\title{
Inverse effect in simultaneous thermal and radiation aging of EVA insulation
}

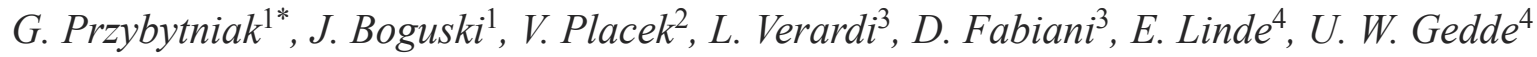 \\ ${ }^{1}$ Institute of Nuclear Chemistry and Technology, Dorodna 16, 03-195 Warsaw, Poland \\ ${ }^{2}$ Ustav Jaderneho Vyzkumu A.S., Husinec - Rež, Hlavní 130, 250 68, Czech Republic \\ ${ }^{3}$ Laboratory of Innovation Technologies (DEI-LIT), University of Bologna, Viale Risorgimento 2, 40136 Bologna, Italy \\ ${ }^{4}$ KTH Royal Institute of Technology, School of Chemical Science and Engineering, Fiber and Polymer Technology, \\ SE-100 44 Stockholm, Sweden
}

Received 11 August 2014; accepted in revised form 29 October 2014

\begin{abstract}
Poly(ethylene-co-vinyl acetate) (EVA) insulation of the cable applied in nuclear power plants was accelerated aged by gamma-rays at two various temperatures, namely 55 and $85^{\circ} \mathrm{C}$. Radiation degradation in the dose range of 0 1500 kGy was monitored using a Differential Scanning Calorimetry method by measuring oxidative induction temperature (OITp), gel fraction, mechanical and electrical tests. It was confirmed that a dose rate effect in the range of 420-1500 Gy/h was negligible whereas progress of degradation with increasing dose was strongly temperature dependent. For the insulation accelerated aged at $85^{\circ} \mathrm{C}$ the OITp and permittivity measurements confirmed lower degradation than for the specimens radiation treated at $55^{\circ} \mathrm{C}$ at the same dose rates. It was postulated that an inverse thermal effect resulted from radiation induced cross-linking facilitated by melting of EVA crystallites at $85^{\circ} \mathrm{C}$.
\end{abstract}

Keywords: material testing, radiation degradation, thermal degradation, inverse thermal effect, poly(ethylene-co-vinyl acetate)

\section{Introduction}

Reliability of the cables operating in Nuclear Power Plant (NPP) is usually estimated by the condition monitoring tests followed by accelerated aging. This approach is necessary as with increasing service time polymers, the crucial components of insulations and jackets, degrade gradually predominantly due to exposure to two adverse stressors associated with gamma radiation and elevated temperatures. In the past, various procedures were implemented for conducting the initial and on-going qualifications of the NPP cables [1].

During accelerated aging performed in the first stage of the procedure, intensities of both degrading factors (i.e. radiation and heating) vary significantly, depending on the possibilities of testing lab- oratories. In spite of the recommendations presented in IAEA reports that the acceleration factor for absorbed dose should not exceed 250 [2], the value in many conducted experiments is often higher and depends on the access to the particular type of gamma chambers equipped with an installation for thermal heating. Additionally, many tests are performed applying periodically heating and exposure to ionizing radiation, in spite of the fact that under real conditions in NPPs both stressors operate simultaneously and that the final effect of degradation varies depending on the applied procedure. Therefore, in our studies the second modus operandi, better suited to the NPP realities, was applied.

It is generally accepted that thermal condition monitoring techniques are convenient for the analysis of

\footnotetext{
$\overline{{ }^{*} \text { Corresponding author, e-mail: g.przybytniak@ichtj.waw.pl }}$

(C) BME-PT
} 
polymer degradation as they are sensitive, accessible, relatively simple and require a small sample weight [3-5]. Additionally, they might be applied for a variety of plastics for which accelerated aging induces changes in the thermal features. In this group of materials is poly(ethylene-co-vinyl acetate) (EVA) being the object of the reported studies. The polymer characterizes high electrical resistivity, low processing temperature and water wettability.

DSC thermograms of EVA reveal two or more peaks corresponding to the ethylene domains of the copolymer. As a semicrystalline material, it shows a very broad melting transition because of wide dispersion of the crystallite sizes and the variety of imperfections in the ordered phase [6, 7]. The DSC method is also used in isothermal mode for measuring oxidative induction time (OIT) related to the copolymer stability [8-10].

The goal of our work was to monitor the influence of dose rate and total dose absorbed at two various temperatures on some parameters characterizing the extent of degradation. In the previous studies we investigated isothermal decay of aged EVA copolymer in aerobic and anaerobic environment. The results strongly suggested that in both cases the effect is determined by dose absorbed and presence of oxygen during measurement [7]. Now we report further studies on the macroscopic effects of oxidative degradation monitored by several selected methods.

The oxidative induction time (OIT) measurements were unsuccessful as the thermograms did not reveal any distinct thermal transitions related to oxidation. Thus, oxidative induction temperatures (OITp) and pre-oxidation phase transitions were investigated in order to demonstrate the capability of the thermal analysis to monitor the actual status of the cable. The data obtained were compared with the results of mechanical and electrical tests as well as gel fraction values.

\section{Experimental}

\subsection{Materials and aging procedure}

The selected insulation was a component of the low voltage measurement cable. The following main constituents of the insulation composite were confirmed: $42 \%$ cross-linked poly(ethylene-co-vinyl acetate) (EVA), flame retardant and inorganic filler, $\mathrm{Al}(\mathrm{OH})_{3}$ and $\mathrm{CaCO}_{3}$ respectively. Initial thermal characteristic of the pristine insulation revealed that the degree of crystallinity of EVA was $9.5 \%$. The value was calculated basing on the DSC measurements using the total enthalpy method, as shown by Equation (1):

$D C=\frac{\Delta H_{\mathrm{m}}}{\Delta H_{100 \%}}$

where $D C$ is the degree of crystallinity, $\Delta H_{\mathrm{m}}$ is the enthalpy of melting of the sample $(27.3 \mathrm{~J} / \mathrm{g})$ and $\Delta H_{100 \%}$ is the enthalpy of melting for $100 \%$ crystalline polyethylene (288 J/g [6]). Additionally, on the basis of TGA measurements it was found that the VA content in the EVA copolymer was about $14 \%$ [11]

The material of the symbol I0 was exposed to accelerated aging in a gamma chamber equipped with a heating installation in the form of thermobox (ROZA facility in Ustav Jaderneho Vyzkumu A.S., Rez, Czech Republik). Thermal and radiation aging was carried out simultaneously.

The dose rate depended on the distance from the centrally located ${ }^{60} \mathrm{Co}$ source. Dosimetry of the particular positions in the chamber was based on the alanine signal detected by EPR spectroscopy [12]. Actual temperature of the cables during irradiation was controlled.

Every $200 \mathrm{~h}$ the samples introduced into the chamber were taken out and investigated by thermal, mechanical and electrical methods.

Accelerated aging processes were performed under the conditions specified in Table 1.

Table 1. Accelerated aging conditions of insulation marked by a symbol I0

\begin{tabular}{|l|c|c|c|c|}
\hline \multirow{2}{*}{ Code } & \multicolumn{3}{|c|}{ Accelerated ageing procedure } \\
\cline { 2 - 5 } & $\begin{array}{c}\text { Temperature } \\
{\left[{ }^{\circ} \mathbf{C}\right]}\end{array}$ & $\begin{array}{c}\text { Radiation dose } \\
{[\mathbf{G y} / \mathbf{h}]}\end{array}$ & $\begin{array}{c}\text { Time } \\
{[\mathbf{h}]}\end{array}$ & $\begin{array}{c}\text { Cumulative dose } \\
{[\mathbf{k G y}]}\end{array}$ \\
\hline I85-A & 85 & 420 & $200 ; 400 ; 600 ; 800 ; 1000$ & $84 ; 168 ; 252 ; 336 ; 420$ \\
\hline I85-B & 85 & 940 & $200 ; 400 ; 600 ; 800 ; 1000$ & $188 ; 376 ; 565 ; 752 ; 940$ \\
\hline I85-C & 85 & 1500 & $200 ; 400 ; 600 ; 800 ; 1000$ & $300 ; 600 ; 900 ; 1200 ; 1500$ \\
\hline I55-B & 55 & 940 & $200 ; 400 ; 600 ; 800 ; 1000$ & $188 ; 376 ; 565 ; 752 ; 940$ \\
\hline I55-C & 55 & 1500 & $200 ; 400 ; 600 ; 800 ; 1000$ & $300 ; 600 ; 900 ; 1200 ; 1500$ \\
\hline
\end{tabular}




\subsection{Thermal measurements}

The thermo-oxidative stability testing was performed using a Differential Scanning Calorimetry apparatus (MDSC 2920 CE TA Instruments). Because the OIT tests failed, the OITp measurements were applied for determining the progress of insulation degradation [7, 13]. Both techniques, among others, monitor the amount of antioxidant remaining in the sample upon aging [14]. Small samples of the insulation (below $10 \mathrm{mg}$ ) placed in an open aluminium pan were inserted into the apparatus oven. The programmable temperature increase was $10^{\circ} \mathrm{C} / \mathrm{min}$ starting from the ambient conditions. The measurements were conducted at an oxygen flow of $50 \mathrm{~mL} / \mathrm{min}$. Analysis of the results was conducted using TA Instruments software - Universal Analysis 2000. Each measurement was repeated at least 3 times.

\subsection{Mechanical tests}

The tensile properties were measured using a load frame testing machine Instron 5565 with extension rate of $50 \mathrm{~mm} / \mathrm{min}$ and initial gauge length of $40 \mathrm{~mm}$ [15]. Samples were conditioned at $25^{\circ} \mathrm{C}$ and $50 \%$ relative humidity for 24 hours prior to testing. For each sample five specimens were tested.

\subsection{Gel fraction}

The gel content was determined for the cross-section segments of insulation. Extraction with xylene in a Soxhlet apparatus was performed according to the standard [16]. Percentage of the insoluble part of the sample containing fillers and $42 \%$ EVA was normalized to the polymer content only. Each measurement was repeated three times.

\subsection{Microstructure characterization}

Microstructure of the starting and accelerated aged samples was examined by Zeiss Ultra-High-Resolution Imaging SEM based on Zeiss' GEMINI field emission SEM column. The microscope had two electron detectors and an energy selective back scattering detector.

\subsection{Electrical tests}

Electrical properties of the aged cable were investigated through dielectric spectroscopy, using a Novocontrol Impedance Analyzer. Frequency ranged between $10^{-2}-10^{6} \mathrm{~Hz}$ with an input voltage of $3 \mathrm{~V}_{\text {rms. }}$. Test temperature was kept at $50^{\circ} \mathrm{C}$.

\section{Results and discussion}

The first OITp measurement was performed for non-aged insulation I0. The recorded thermogram revealed two broad endothermic peaks attributed to two types of crystallites of various size and lattice defects, Figure 1. Shi et al. [17] reported that for EVA the peaks were located in two ranges - lower transition temperature was situated at $40-60^{\circ} \mathrm{C}$ and higher transition temperature in the range of 80 $90^{\circ} \mathrm{C}$. Generally, it is assumed that the larger crystals of better-defined structure show higher melting temperatures which in the case of studied EVA insulation corresponds to the transition showing maximal temperature $\left(T_{\mathrm{m}}\right)$ at about $89^{\circ} \mathrm{C}$. The low temperature transition is situated at around $75^{\circ} \mathrm{C}$ what indicates that there are not small crystallites having melting points below $60^{\circ} \mathrm{C}$.

For the insulation accelerated aged with dose rates of 940 or $1500 \mathrm{~Gy} / \mathrm{h}$ at $55^{\circ} \mathrm{C}$ enthalpy of fusion determined for the transitions extended from 55 to $100^{\circ} \mathrm{C}$ increases from 22.3 to about $28.2 \mathrm{~J} / \mathrm{g}$ for the most severely damaged samples. The representative example of the thermogram (I55-C; $1200 \mathrm{kGy}$ ) is shown in Figure 1. For aging performed at $55^{\circ} \mathrm{C}$ the variations in the maxima of phase transition temperature $\left(T_{\mathrm{m}}\right)$ are situated in the narrow range of $89.5-91.3^{\circ} \mathrm{C}$. Intensity of the peak increases, contrary to the low-temperature thermal effect which almost disappears. It seems that the crystallites change structure and their population grows as might be concluded from almost $30 \%$ increase in the enthalpy of fusion. The last effect might be attributed to the radiation induced scission of tie macromolecules resulting in a growth of crystalline

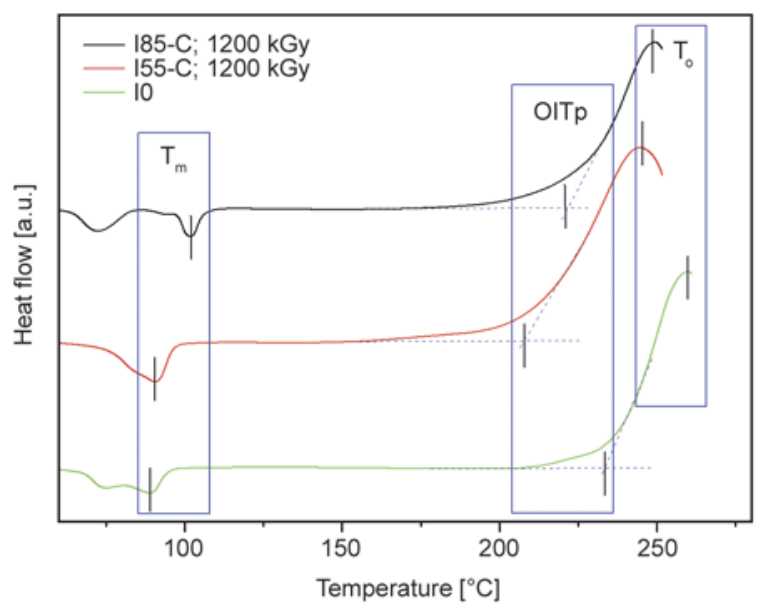

Figure 1. Examples of thermograms measured under oxygen flow for EVA insulation before and after accelerated aging 

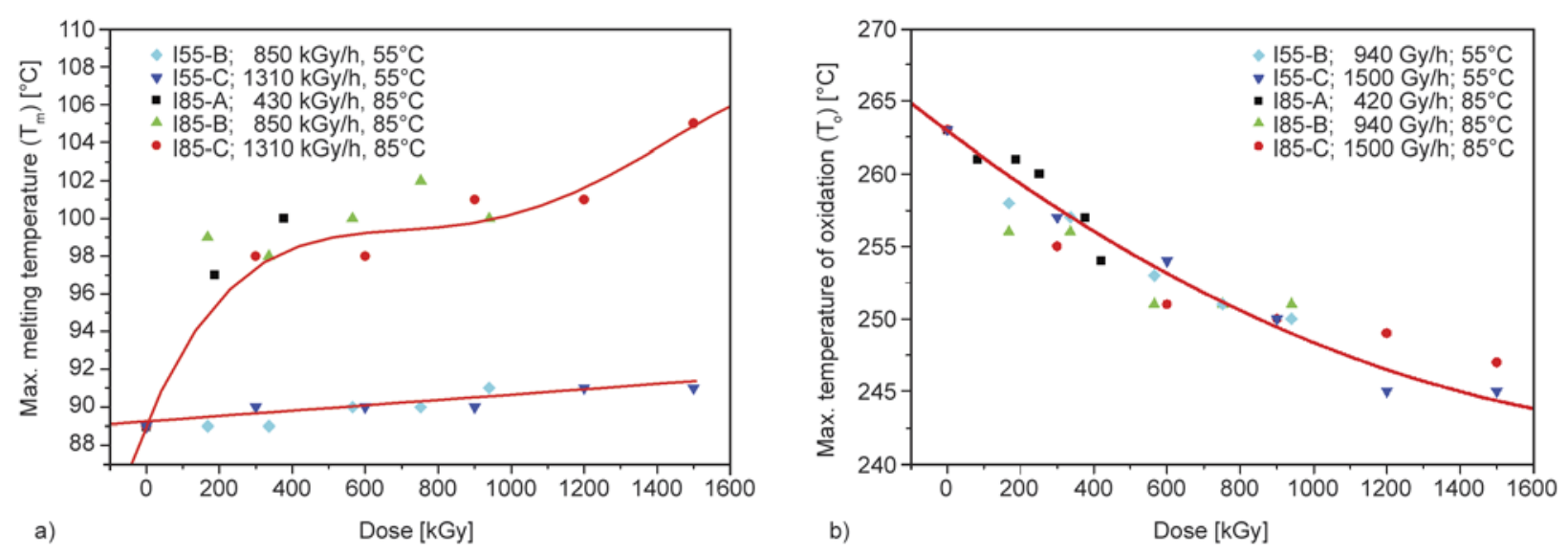

Figure 2. (a) Maximum melting temperatures $\left(T_{\mathrm{m}}\right)$ as a function of dose for EVA insulation aged under various conditions. (b) Maximum oxidation temperatures $\left(T_{\mathrm{o}}\right)$ as a function of dose for EVA insulation aged under various conditions. Average temperatures were determined on the basis of 3 independent measurements. The margin of error is $\pm 1,5^{\circ} \mathrm{C}$.

size and eventually in the increase of the content of ordered phase [18].

The thermograms are changing substantially when aging is performed at $85^{\circ} \mathrm{C}$, i.e. at temperature corresponding to the melting state of a significant part of crystalline phase. The endothermic high-temperature transitions are shifted towards higher temperatures and Tm increases of at least $8 \mathrm{deg}$ in comparison with Tm found for the initial sample, Figure 2a. Observed upon aging shift towards higher temperatures is usually attributed to the growth of structural regularity and to the enhanced crystal thickness. Due to continuous heat supply at $85^{\circ} \mathrm{C}$ melting is not only a surface process and the interior of the crystals is also involved in the structural changes. Reaching thermal equilibrium, all crystallites showing melting points smaller than the annealing temperature are melted. During cooling they form new crystallites of melting points higher or lower than the annealing temperature [11]. Additionally, under such conditions the original crystals having melting temperature higher than $85^{\circ} \mathrm{C}$ continuously improve their structure in the reorganization process [19]. These phenomena correspond to the temperature dependent isothermal recrystallization. In such circumstances, enthalpy of fusion should increase due to favorable conditions for the formation of well defined, larger crystals. Nevertheless, simultaneously gamma-radiation induces defects of the polymer macromolecules and for this reason the resultant degree of crystallinity does not increase in this case. We suggest that crystallites melted at $85^{\circ} \mathrm{C}$, when exposed to ionizing radiation, are more susceptible

to cross-linking due to intense conformational movements. The effect was confirmed earlier for some other polymers, e.g. polytetrafuoroethylene [20]. Contrary to above findings, the maximum oxidation temperature $T_{\mathrm{o}}$ (see Figure 1) decreases almost monotonically with dose, and both dose rates and temperatures of accelerated aging do not influence significantly the parameter, Figure $2 b$.

Changes in OITp determined for the accelerated aged insulation are presented in Figure $3 a$ and $3 b$. The significant reduction of the values with increasing dose was confirmed for aging conducted both at 55 and at $85^{\circ} \mathrm{C}$; the OITp decrease even up to about 30 and $20^{\circ} \mathrm{C}$ was found, respectively. On the other hand, the influence of applied dose rates at lower temperature was negligible and at higher one barely noticeable. The results suggest that the nature of the processes for dose rates situated in the range of $420-1500 \mathrm{~Gy} / \mathrm{h}$ is generally the same.

Thermal oxidative degradation of EVA measured by OITp involves at the first stage deacetylation followed by concurrent oxidation [21]. The elimination of acetic acid is possible via catalytic or noncatalytic reaction [22]. Hydroperoxides are important products of degradation that are converted into ketone groups in autooxidation process. When the EVA copolymer was oven aged at $180^{\circ} \mathrm{C}$ [23] other oxygen containing groups like hydroxyl, lactones, anhydride were confirmed by FTIR spectroscopy. It was also found that degradation leading to the creation of hydroperoxides prompts the formation of polyconjugated carbonyl groups resulting in color change [24]. All these processes and their contribu- 

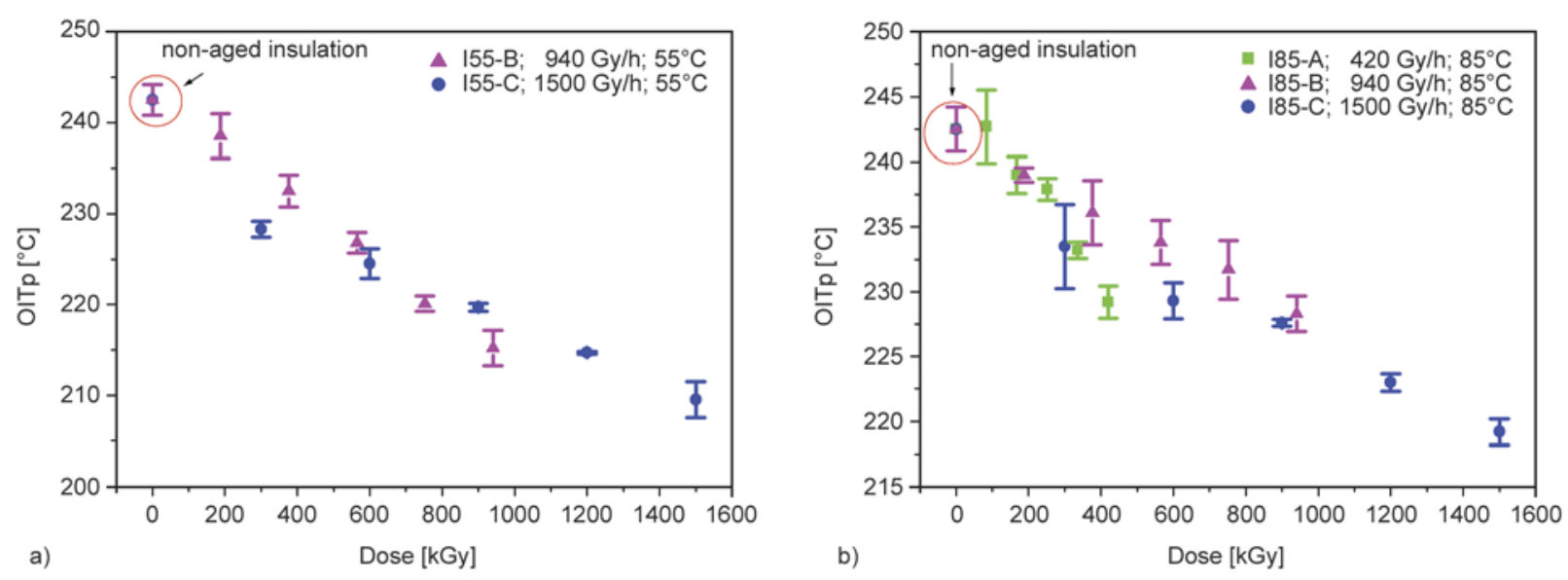

Figure 3. Relationship between dose absorbed by insulation and OITp values for various dose rates. (a) aging carried out at $55^{\circ} \mathrm{C}$, (b) aging carried out at $85^{\circ} \mathrm{C}$

tion in the exothermic oxidation observed above $200^{\circ} \mathrm{C}$ by OITp depend on the extent of degradation occurring during aging.

Interestingly, as shown in Figure 4, the gradual reduction of OITp is strongly temperature dependent. For both compared dose rates, 940 and $1500 \mathrm{~Gy} / \mathrm{h}$, the observed consequences of aging monitored by OITp are much severe for 55 than for $85^{\circ} \mathrm{C}$. Based on these relationships we suggest that in the studied system the inverse thermal effect is observed and that thermal aging and radiation aging cause neither additive nor synergetic effects. Similar changes were observed in the past by Celina et al. [25] for semi-crystalline polyolefin.

At higher temperature $\left(85^{\circ} \mathrm{C}\right)$ degradation measured by OITp is smaller than at lower one $\left(55^{\circ} \mathrm{C}\right)$ what confirms our earlier assumption that radiation effects in the molten state are fundamentally different than in crystallites and that this dissimilarity results in abnormal behavior of the accelerated aged

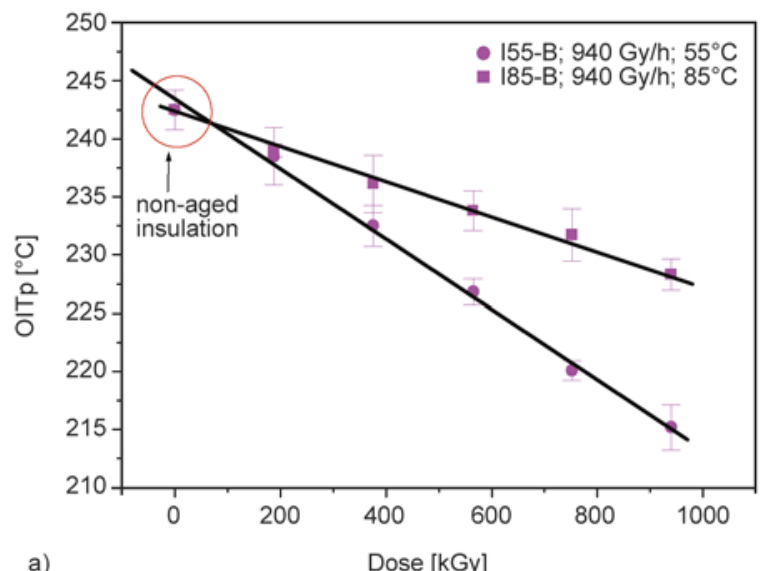

insulation. Postulated cross-linking not only increases thermooxidative stability but also hinders the diffusion of oxygen necessary for oxidative degradation. The inverse effect seems to be deeper for the lower dose rate, i.e. for $940 \mathrm{~Gy} / \mathrm{h}$, than for $1500 \mathrm{~Gy} / \mathrm{h}$, as in the first case the charts illustrating dependence OITp vs. dose diverge from each other to a greater extent.

For the samples exposed to accelerated aging the beginning of oxidation determined on the basis of OITp requires higher temperatures at the same absorbed dose than for the insulation radiation treated at $55^{\circ} \mathrm{C}$ what has to be the consequence of some structural obstacles. Thus, intermolecular bonds radiation generated in the molten crystals result in hindering exothermic oxidative processes identified above $200^{\circ} \mathrm{C}$, as is apparent from Figures 1 and 4 . Radiation degradation of EVA copolymer refers primarily to the acetate regions. Murat Şen and Mehmet Copuroğlu concluded on the basis of FTIR analysis

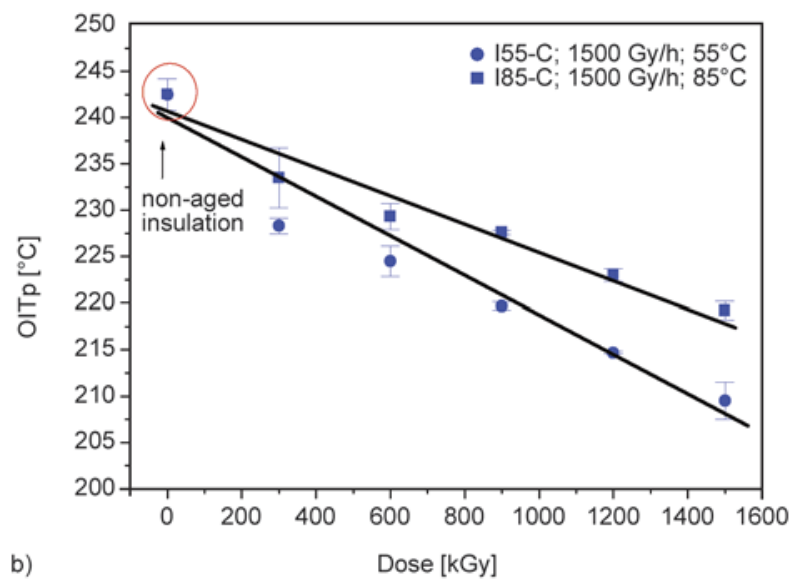

Figure 4. OITp as a function of dose absorbed for irradiations performed at 55 and $85^{\circ} \mathrm{C}$ with a dose rate of $940 \mathrm{~Gy} / \mathrm{h}$ (a) and $1500 \mathrm{~Gy} / \mathrm{h}(\mathrm{b})$ 
that main products of gamma degradation were conjugate dienes and ketones [26]. Subsequently, according to Norrish I and Norrish II reactions the second species might in the multistage processes form carboxylic acid, lacton, ester or vinyl groups [27]. The total effect of oxidative degradation depends on the access to oxygen that is controlled, among others, by aging temperature. Generally for gases, solubility decreases with an increase in temperature, whereas diffusion changes in opposite direction [28]. Usually the second effect in semi-crystalline polymers is studied in terms of a spatial distribution of the impermeable crystalline phase and the permeable amorphous phase, which are cross-linked by tie chains or by intermolecular bonds. However, in our studies the melting of EVA crystals at $85^{\circ} \mathrm{C}$ partly removes this limitation. Due to topological differences of EVA at various temperatures and eventually not the same oxidation conditions, our assumption that it

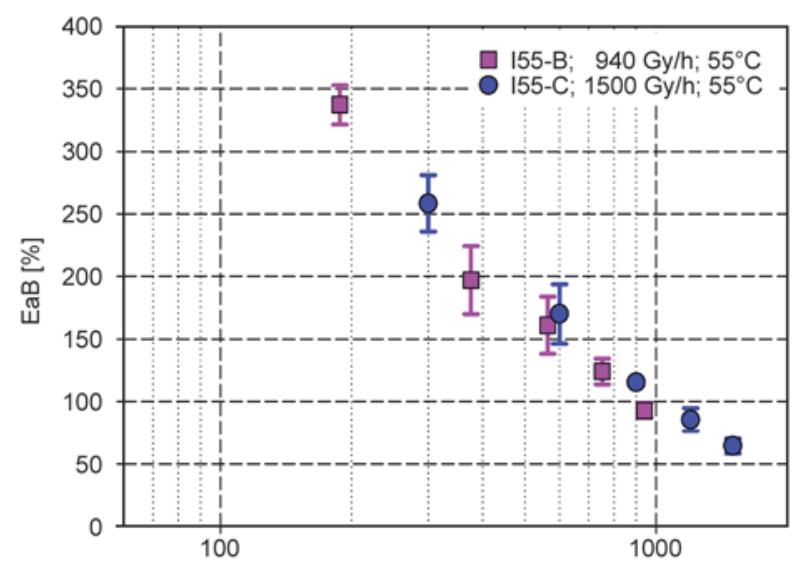

a)

Dose [kGy] increasing contribution of cross-linking induces 'inverse effect' requires further evidences.

Mechanical properties also exhibit an interesting relationship with aging. In particular, Figure 5 shows elongation at break (EaB) vs. dose for the samples irradiated at $55^{\circ} \mathrm{C}$ (Figure 5a) and at $85^{\circ} \mathrm{C}$ (Figure 5 b), with dose rates of 420,940 or $1500 \mathrm{~Gy} / \mathrm{h}$. As can be seen, the influence of dose rate on the $\mathrm{EaB}$ decrease with dose absorbed is negligible in the range of doses herein investigated, confirming the OITp results presented in Figure 3. The effect of temperature is shown in Figure 6, which presents plots the $\mathrm{EaB}$ values as a function of dose absorbed for the samples irradiated at 55 and $85^{\circ} \mathrm{C}$, with fixed dose rates of $940 \mathrm{~Gy} / \mathrm{h}$ (Figure 6a) and $1500 \mathrm{~Gy} / \mathrm{h}$ (Figure 6b). The slope of EaB decrease with dose is higher for insulation aged at 85 than at $55^{\circ} \mathrm{C}$. It should be noted that the steep decrease of $\mathrm{EaB}$, particularly at $85^{\circ} \mathrm{C}$ can be associated both with cross-

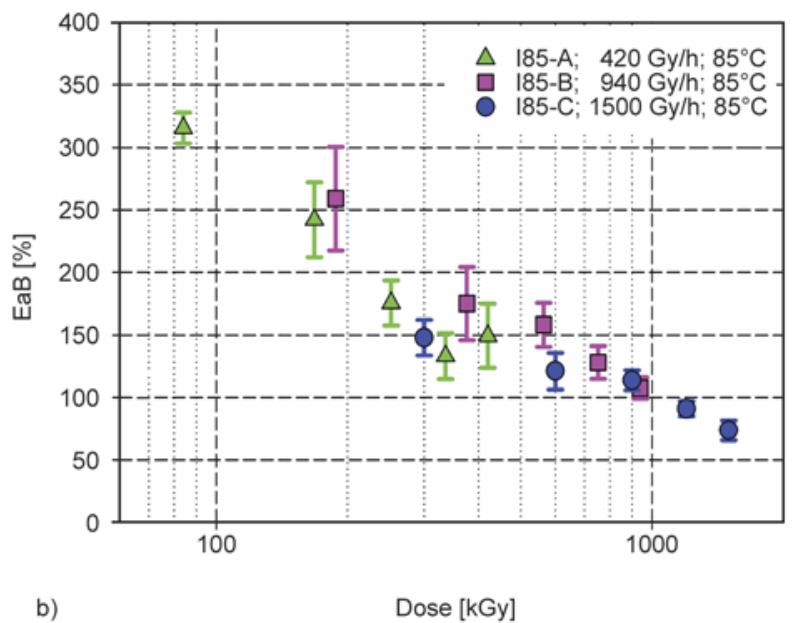

b)

Figure 5. Elongation at break vs. dose for samples irradiated at $55^{\circ} \mathrm{C}$ (a) and $85^{\circ} \mathrm{C} \mathrm{(b),} \mathrm{with} \mathrm{dose} \mathrm{rates} \mathrm{of} 420 \mathrm{~Gy} / \mathrm{h}$, $940 \mathrm{~Gy} / \mathrm{h}$ and $1500 \mathrm{~Gy} / \mathrm{h}$
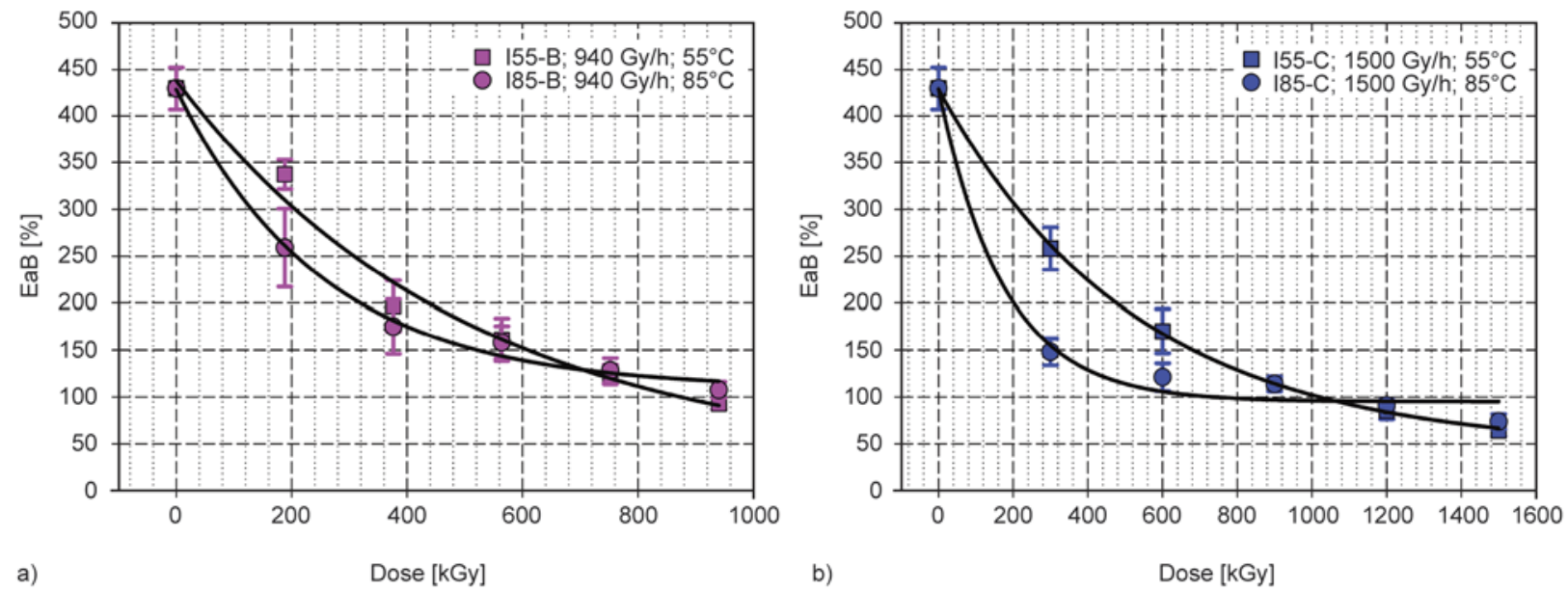

a) Dose [kGy]

Figure 6. Elongation at break vs. dose for samples irradiated at 55 and $85^{\circ} \mathrm{C}$, with dose rates of $940 \mathrm{~Gy} / \mathrm{h}$ (a) and $1500 \mathrm{~Gy} / \mathrm{h}(\mathrm{b})$ 


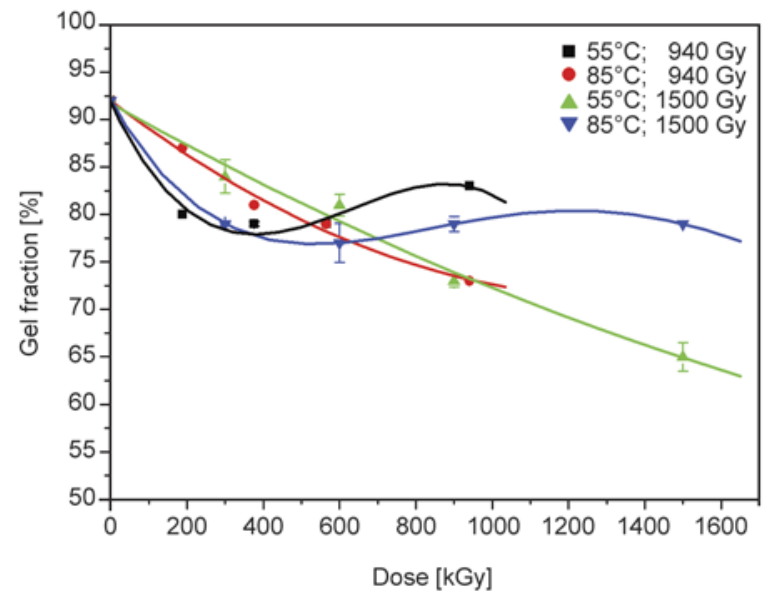

Figure 7. Gel fraction versus doses absorbed for polymeric matrix of insulation accelerated aged under various conditions

linking and with chain scission occurring during aging, thus the results are not conclusive with respect to the search for inverse effect evidences.

Gel fraction determined for the initially cross-linked polymeric matrix decreases almost proportionally to the growth of doses for both dose rates if aging temperature is fixed at $55^{\circ} \mathrm{C}$, Figure 7 . The relationship changes when irradiation is performed at $85^{\circ} \mathrm{C}$. An initial decline of gel fraction of almost $15 \%$ is followed by the clear increase for the doses above $400 \mathrm{kGy}$ and then the insoluble part of EVA remains higher than for specimens aged at $55^{\circ} \mathrm{C}$. The tendency is unambiguous and corresponds to the correlations found for OITp vs. dose absorbed. Irradiation at both studied temperatures obviously induces degradation of the polymeric matrix and this effect prevails over cross-linking. However, the yield of the second process is higher at 85 than at $55^{\circ} \mathrm{C}$ what

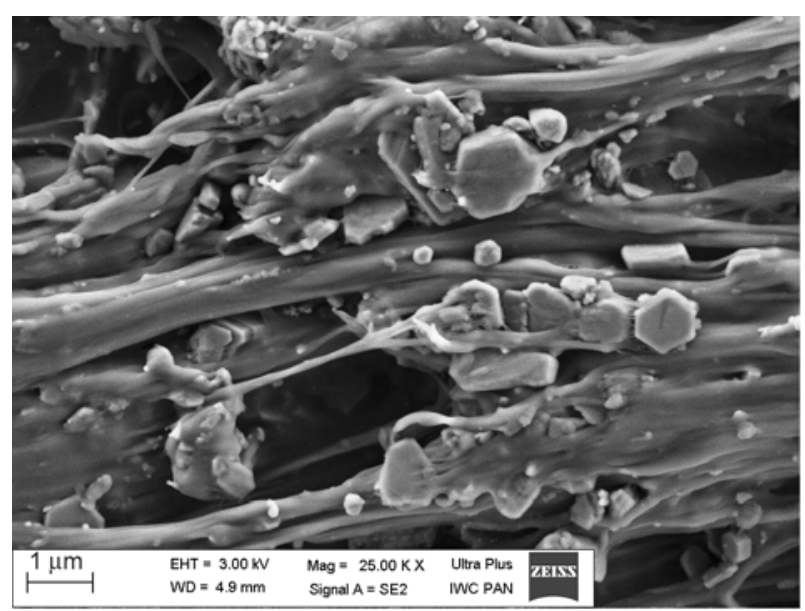

a) diversifies macroscopic properties of the aged insulation. The conclusion on enhanced cross-linking at elevated temperature additionally supports a decrease in the degree of crystallinity determined on the basis of melting transitions recorded during the first and second DSC cycle, e.g. for the sample $185^{\circ} \mathrm{C}$ irradiated with a dose of $1200 \mathrm{kGy}$ crystallinity diminishes from 7.5 to $5.0 \%$, respectively.

SEM studies were carried out for fractures of the non-aged insulation I0 and for the sample radiation aged at $85^{\circ} \mathrm{C}$ to a dose of $1200 \mathrm{kG}$ at a dose rate of $1500 \mathrm{~Gy} / \mathrm{h}$, Figure 8 . The images reveal inhomogeneous structure of the composites constructed from continuous polymeric matrix doped with inorganic particles of various sizes. It seems that for aged insulation the copolymer tightly adheres to the fillers and that the phase separation in this case is reduced in comparison with the starting sample. It could be a result of the reorganisation of the polymer during thermal and radiation aging, including cross-linking.

The measurement of electrical quantities, like e.g. imaginary permittivity, provides further confirmation of the results obtained from measuring OITp and gel fraction. Indeed, negligible variation of imaginary permittivity with the dose rate can be observe at fixed temperature (Figure 9) while at fixed dose rate (Figure 10) the imaginary permittivity increases more steeply at 55 than at $85^{\circ} \mathrm{C}$, showing again the inverse temperature effect.

\section{Conclusions}

1. OITp measurements are convenient condition monitoring method for studding cable degrada-

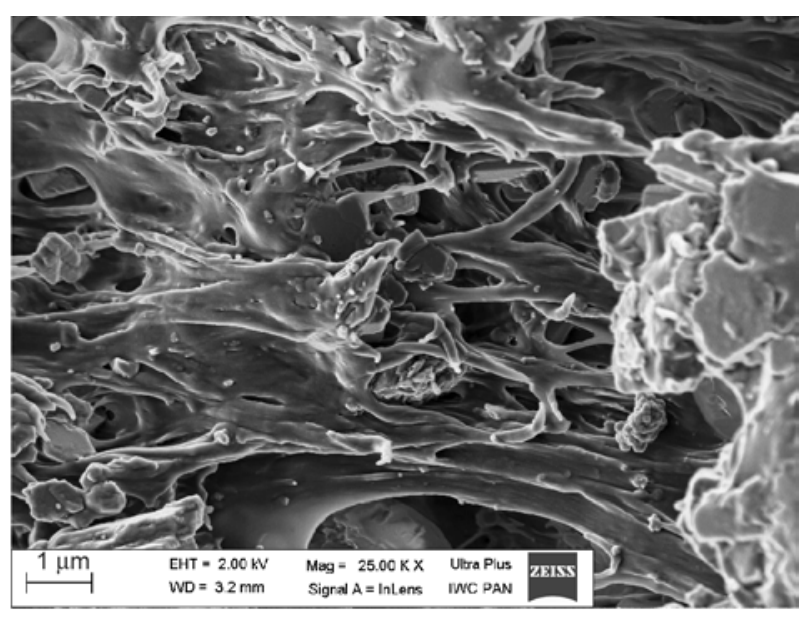

b)

Figure 8. The examples of SEM images recorded for the fractures of pristine sample I0 (a) and sample aged at $85^{\circ} \mathrm{C}$ with a dose of $1200 \mathrm{kGy}$ at $1500 \mathrm{~Gy} / \mathrm{h}$ (b) 

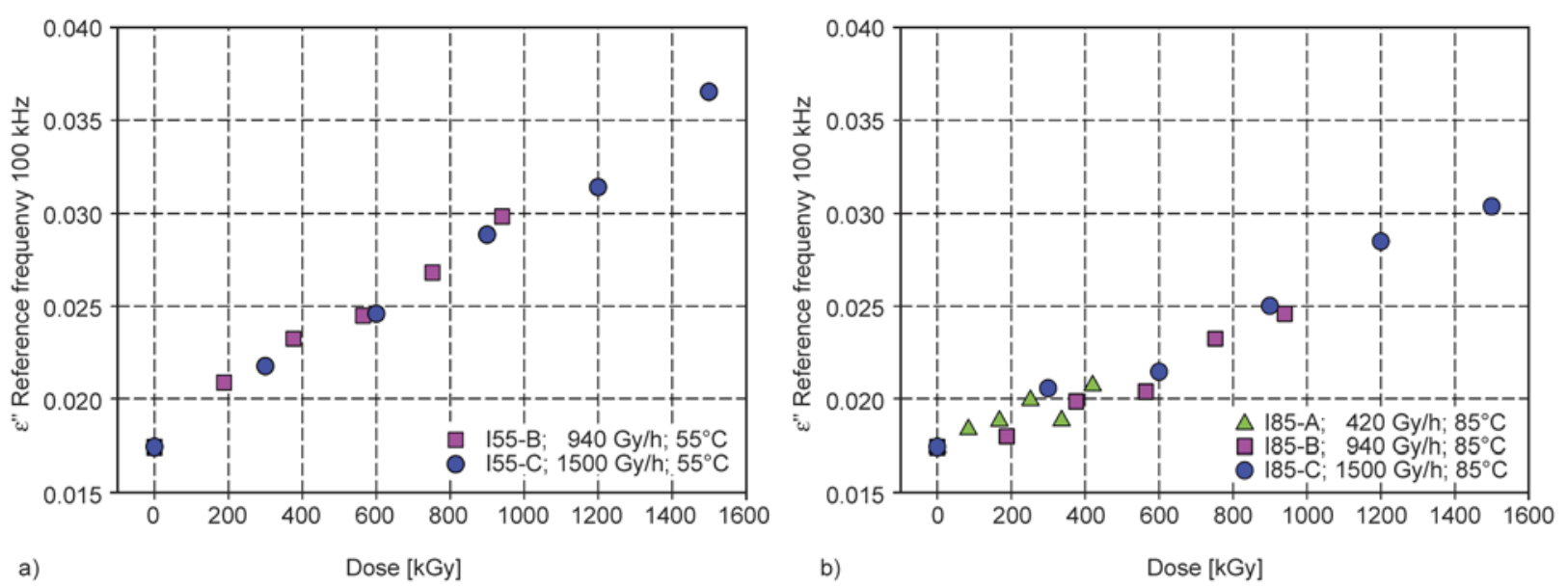

Figure 9. Imaginary part of permittivity $(105 \mathrm{~Hz})$ vs. dose for samples irradiated at $55^{\circ} \mathrm{C}$ (a) and $85^{\circ} \mathrm{C}$ (b), with dose rates of 420,940 and $1500 \mathrm{~Gy} / \mathrm{h}$

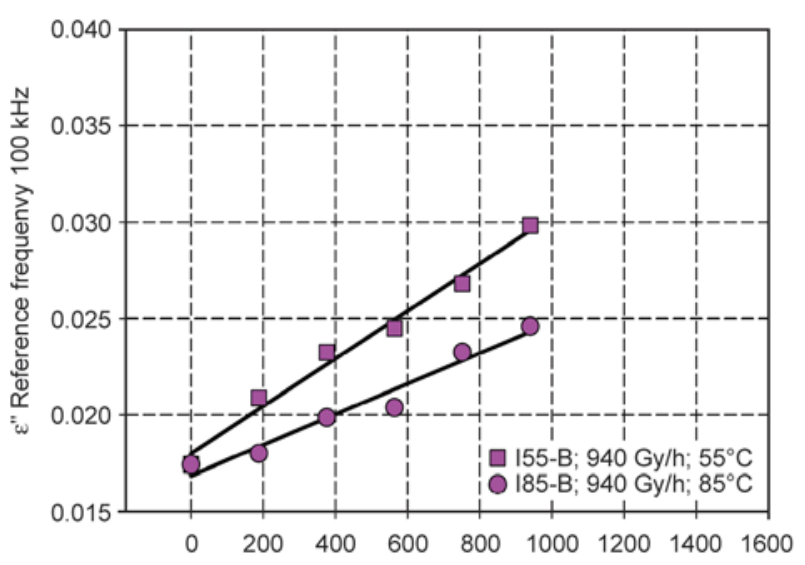

a)

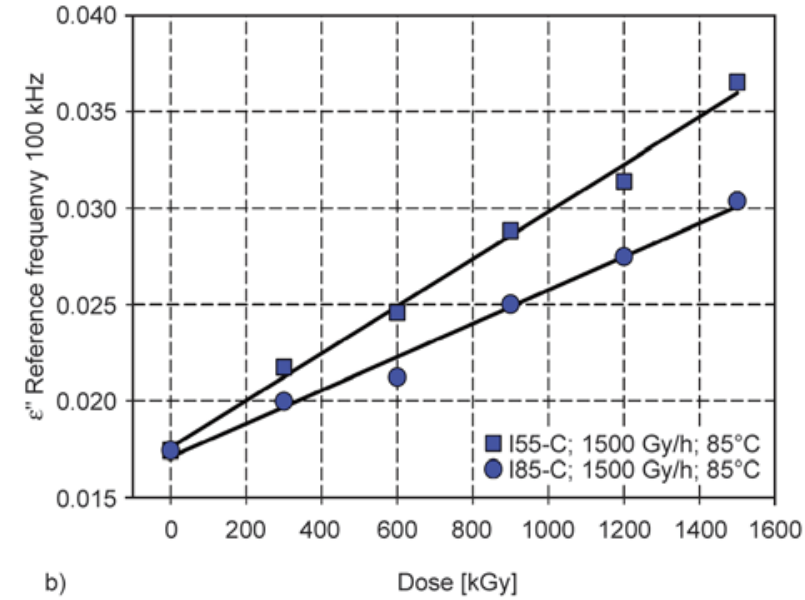

Figure 10. Imaginary part of permittivity $(105 \mathrm{~Hz})$ vs. dose for samples irradiated at 55 and $85^{\circ} \mathrm{C}$, with dose rates of $940 \mathrm{~Gy} / \mathrm{h}(\mathrm{a})$ and $1500 \mathrm{~Gy} / \mathrm{h}$ (b)

tion, especially when OIT tests do not provide reliable results.

2. For EVA insulation the extent of thermal and radiation induced aging performed simultaneously is a function of temperature and dose, whereas the effect of applied dose rates is insignificant (420 $1500 \mathrm{~Gy} / \mathrm{h}$ ).

3. Accelerated radiation aging conducted at the temperatures corresponding to melting points of the polymer crystallites (or higher) leads to the inconsistent conclusions which cannot be applied for the simulation of anticipated aging of the cables installed in NPPs and for the prediction of their lifetime. In this instance, the extrapolation of OITp values underestimates destruction effects expected at lower temperatures encountered in hot spots of reactors surrounding.

4. Electrical measurements, contrary to mechanical tests, provide results consistent with thermal analysis and gel fraction results confirming that the accelerated degradation of cable insulation strongly depends on the accelerated aging procedure applied to the specimens.

5. For the thermally and radiation aged EVA insulation an inverse thermal effect was confirmed by OITp, dielectric permittivity and gel fraction measurements. The phenomenon is associated with heating of the semicrystalline polymer in the range of melting endotherm during radiation treatment. It seems that such an aging procedure promotes radiation induced cross-linking limiting polymer degradation and hindering oxidation determined by the oxidative induction temperature measurements.

6. The temperature depended changes of EVA morphology influence mechanisms of radiation induced processes and eventually affect macro- 
scopic features determined by some thermal, mechanical and electrical techniques.

\section{Acknowledgements}

The work has been performed in the frame of 7th FP project: 'Aging Diagnostics and Prognostics of low-voltage I\&C cables', grant agreement No 269893. Polish participation was co-financed by the Polish Ministry of Science and Higher Education, Grant Agreement No 2055. Matthias Meyer, Nexans is thanked for providing the cable used in this study.

\section{References}

[1] Assessing and managing cable aging in nuclear power plants. IAEA, Nuclear Energy Series, No. NP-T-3.6, Wien (2012).

[2] Assessment and management of aging of major nuclear power plant components important to safety: In-containment instrumentation and control cables. Volume I. IAEA-TECDOC-1188, Wien (2000).

[3] Bartoníček B., Hnát V., Plaček V.: Life-assessment technique for nuclear power plant cables. Radiation Physics and Chemistry, 52, 639-642 (1998).

DOI: 10.1016/S0969-806x(98)00172-8

[4] Calmet J. F., Carlin F., Nguyen T. M., Bousquet S., Quinot P.: Irradiation ageing of CSPE/EPR control command electric cables. Correlation between mechanical properties and oxidation. Radiation Physics and Chemistry, 63, 235-239 (2002).

DOI: 10.1016/S0969-806x(01)00585-0

[5] Rosa D. S., Sarti J., Mei L. H. I., Filho M. M., Silveir S.: A study of parameters interfering in oxidative induction time (OIT) results obtained by differential scanning calorimetry in polyolefin. Polymer Testing, 19, 523-531 (2000).

DOI: 10.1016/S0142-9418(99)00022-7

[6] Agroui K., Collins G.: Determination of thermal properties of crosslinked EVA encapsulant material in outdoor exposure by TSC and DSC methods. Renewable Energy, 63, 741-746 (2014).

DOI: $10.1016 /$ j.renene.2013.10.013

[7] Boguski J., Przybytniak G., Łyczko K.: New monitoring by thermogravimetry for radiation degradation of EVA. Radiation Physics and Chemistry, 100, 49-53 (2014).

DOI: $10.1016 /$ j.radphyschem.2014.03.028

[8] Riga A., Collins R., Mlachak G.: Oxidative behavior of polymers by thermogravimetric analysis, differential thermal analysis and pressure differential scanning calorimetry. Thermochimica Acta, 324, 135-149 (1998). DOI: 10.1016/S0040-6031(98)00530-9

[9] Woo L., Ling M. T. K., Ding S. Y., Westphal S. P.: Effect of ionizing radiation on the thermal oxidative stability of medical polymers. Thermochimica Acta, 324, 179-185 (1998). DOI: $10.1016 / \mathrm{S} 0040-6031(98) 00534-6$
[10] Woo L., Sandford C. L.: Comparison of electron beam irradiation with gamma processing for medical packaging materials. Radiation Physics and Chemistry, 63, 845-850 (2002). DOI: $10.1016 / \mathrm{S} 0969-806 x(01) 00664-8$

[11] Menczel J. D., Prime R. B.: Thermal analysis of polymers. Fundaments and Applications. Wiley, Hoboken (2009).

[12] ISO/ASTM 51607-04: Standard practice for use of the alanine-epr dosimetry system (2012).

[13] ASTM D3895: Standard test method for oxidativeinduction time of polyolefins by differential scanning calorimetry (2004).

[14] Plaček V., Bartoniček B.: The dose rate effect and the homogeneity of radio-oxidation of plastics. Nuclear Instruments and Methods in Physics Research Section B: Beam Interactions with Materials and Atoms, 185, 355-359 (2001).

DOI: $10.1016 / \mathrm{S} 0168-583 \mathrm{X}(01) 00943-0$

[15] IEC/IEEE 62582-3: Nuclear power plants - Instrumentation and control important to safety - Electrical equipment condition monitoring methods - Part 3: Elongation at break (2012).

[16] ASTM D2765 Determination of gel content and swell ratio of crosslinked ethylene plastics (2006).

[17] Shi X-M., Zhang J., Li D-R., Chen S-J.: Effect of dampheat aging on the structures and properties of ethylenevinyl acetate copolymers with different vinyl acetate contents. Journal of Applied Polymer Science, 12, 2358-2365 (2009).

DOI: $10.1002 / A p p .29659$

[18] Kostoski D., Stojanović Z.: Radiation-induced crystallinity changes and melting behavior of drawn isotactic polypropylene. Polymer Degradation and Stability, 47, 353-356 (1995).

DOI: $10.1016 / 0141-3910(94) 00126-X$

[19] Stark W., Jaunich M.: Investigation of ethylene/vinyl acetate copolymer (EVA) by thermal analysis DSC and DMA. Polymer Testing, 30, 236-242 (2011).

DOI: $10.1016 /$ j.polymertesting.2010.12.003

[20] Seguchi T.: New trend of radiation application to polymer modification - Irradiation in oxygen free atmosphere and at elevated temperature. Radiation Physics and Chemistry, 57, 367-371 (2000). DOI: $10.1016 / \mathrm{S} 0969-806 x(99) 00406-5$

[21] Patel M., Pitts S., Beavis P., Robinson M., Morrell P., Khan N., Khan I., Pockett N., Letant S., von White II G., Labouriau A.: Thermal stability of poly(ethyleneco-vinyl acetate) based materials. Polymer Testing, 32, 785-793 (2013).

DOI: $10.1016 /$ j.polymertesting.2013.03.014

[22] Rimez B., Rahier H., Van Assche G., Artoos T., Biesemans M., Van Mele B.: The thermal degradation of poly(vinyl acetate) and poly(ethylene-co-vinyl acetate), Part I: Experimental study of the degradation mechanism. Polymer Degradation and Stability, 93, 800-810 (2008).

DOI: $10.1016 /$ j.polymdegradstab.2008.01.010 
[23] Allen N. S., Edge M., Rodriguez M., Liauw C. M., Fontan R.: Aspects of the thermal oxidation of ethylene vinyl acetate copolymer. Polymer Degradation and Stability, 68, 363-371 (2000). DOI: $10.1016 / \mathrm{S} 0141-3910(00) 00020-3$

[24] Allen N. S., Edge M., Rodriguez M., Liauw C. M., Fontan R.: Aspects of the thermal oxidation, yellowing and stabilisation of ethylene vinyl acetate copolymer. Polymer Degradation and Stability, 71, 1-14 (2001). DOI: 10.1016/S0141-3910(00)00111-7

[25] Celina M., Gillen K. T., Wise J., Clough R. L.: Anomalous aging phenomena in a crosslinked polyolefin cable insulation. Radiation Physics and Chemistry, 48, 613-626 (1996).

DOI: $10.1016 / 0969-806 x(96) 00083-7$
[26] Şen M., Copuroğlu M.: A comparative study of gamma irradiation of poly(ethylene-co-vinyl acetate) and poly (ethylene-co-vinyl acetate)/carbon black mixture. Materials Chemistry and Physics, 93, 154-158 (2005). DOI: $10.1016 /$ j.matchemphys.2005.03.005

[27] Scaffaro R., Botta L., Gallo G.: Photo-oxidative degradation of poly(ethylene-co-vinyl acetate)/nisin antimicrobial films. Polymer Degradation and Stability, 97, 653-660 (2012).

DOI: 10.1016/j.polymdegradstab.2012.01.003

[28] Rogers C. E.: Permeation of gases and vapours in polymers. in 'Polymer permeability' (Ed.: Comyn J.) Chapman and Hall, London, 11-73 (1985). DOI: $10.1007 / 978-94-009-4858-72$ 